\title{
Encapsulation of l-menthol in hydroxypropyl- $\beta$-cyclodextrin and release characteristics of the inclusion complex
}

\author{
Guangyong Zhu' ${ }^{1}$ Zuobing Xiao ${ }^{1 *}$, Guangxu $\mathrm{Zhu}^{2}$, Rujunzhou ${ }^{1}$, Yunwei Niu${ }^{1}$ \\ ${ }^{1}$ Shanghai Institute of Technology, No. 100 Haiquan Road, Shanghai, 201418, PR China \\ ${ }^{2} 14846,43$ Ave. Edmonton, Alberta, T6H 5S1, Canada \\ "Corresponding author: e-mail: zbingxiao@sina.com
}

\begin{abstract}
1-menthol has been widely used in flavour, food and pharmaceuticals. Because of its high volatility and whisker growth, l-menthol-hydroxypropyl- $\beta$-cyclodextrin inclusion complex was produced to improve shelf-life, provide protection, and enhance the stability of l-menthol. The inclusion complex was characterized by Fourier transform infrared spectroscopy, X-ray diffraction. The results show that 1-menthol was successfully encapsulated in hydroxypropyl- $\beta$-cyclodextrin. 1-menthol loading capacity is about $8.44 \%$. Geometries and binding energies of l-menthol-hydroxypropyl- $\beta$-cyclodextrin inclusion complexes were investigated using molecular mechanics calculations. The shape and orientation of the most stable complex, and the minimum binding energy were determined. L-menthol release from complex was determined by thermogravimetric analysis. Two l-menthol release rate peaks were observed at 69.3 and $279.1^{\circ} \mathrm{C}$. The l-menthol release reaction order, release activation energy and the preexponential factor were obtained.
\end{abstract}

Keywords: 1-menthol, inclusion complex, release characteristics, binding energy, release kinetics.

\section{PRACTICAL APPLICATION}

1-menthol is a monocyclic alcohol found in peppermint and other mint oils, cranberry, cabbage, lemon peel oil, pineapple, thymus, egg, rum, cocoa, tea, honey, avocado, and so on. It has a peppermint-like odor and exerts a cooling sensation when applied to skin and mucosal surfaces. 1-menthol has been widely used in flavor, foods, pharmaceuticals, toothpastes, and tobacco, with secondary applications in chewing gum, cosmetics, and confectionery ${ }^{1,2}$. In certain medications, 1 -menthol is used to treat sunburns, as it provides a cooling sensation. l-menthol is also included in nonprescription products for short-term relief of minor sore throat and minor mouth or throat irritation ${ }^{3}$. Furthermore, 1-menthol can reduce incidence rates of a variety of cancers (e.g. bladder and prostate cancers), due to strong anti-inflammatory and oxygen-quenching abilities. Pretreatment with l-menthol at various doses significantly suppressed tumor formation and growth, and markedly reduced tumor incidence and volume ${ }^{4}$. However, its high volatility and whisker growth are very important problems for its applications and shelf life $^{5}$. Encapsulation technology can solve the problems. It can provide protection and prevent the loss of volatile core materials. Therefore, it can improve shelf-life and enhance the stability of the entrapped ingredients ${ }^{6-8}$.

Cyclodextrins (CDs) have been used extensively in encapsulation research. Because of a hydrophobic inner cavity and a hydrophilic outer surface, CDs can encapsulate hydrophobic compounds with suitable dimensions. The inclusion complexes formed by CDs and volatile or unstable molecules can achieve prolonged shelf-life and high temperature stability ${ }^{2}$. Furthermore, CDs possess a special ability to complex with drugs enabling them to increase solubility, reduce bitterness, and decrease tissue irritation upon dosing ${ }^{10,11}$. Among the numerous CDs and their derivatives, hydroxypropyl- $\beta$-cyclodextrin $(\mathrm{HP}-\beta-\mathrm{CD})$ is a hydroxyalkylated cyclodextrin and has been widely used to increase the solubility, stability, and bioavailability of drugs, because it has more water solubility and low toxicity ${ }^{12,13}$.

In this paper, 1-menthol-HP- $\beta$-CD inclusion complexes were produced and characterized by Fourier transform infrared (FTIR) spectroscopy, X-ray diffraction (XRD). Geometries of 1-menthol-HP- $\beta$-CD inclusion complexes were optimized using molecular mechanics (MM) calculations. The l-menthol release characteristics from the l-menthol-HP- $\beta$-CD inclusion complexes and kinetic parameters were determined using thermogravimetric (TG) analysis.

\section{EXPERIMENTAL}

\section{Material}

1-menthol (with content 99\%) was purchased from the Peking University Zoteq Co. Ltd. HP- $\beta$-CD (with content 99\%) was obtained from Fisher Scientific. Anhydrous ethanol (AR) was purchased from Sinopharm Chemical Reagent Co. Ltd (Shanghai, China).

\section{Preparation of l-menthol-HP- $\beta-C D$ inclusion complex}

The method of preparation of 1-menthol-HP- $\beta-C D$ inclusion complex was adopted as described in literatures $^{14-16} .10 \mathrm{~g}$ of HP- $\beta$-CD was dissolved in $20 \mathrm{~g}$ of deionized water. The temperature was kept at $45^{\circ} \mathrm{C}$. Then $2 \mathrm{~g}$ l-menthol was slowly added to the HP- $\beta$-CD solution. The mixture was continuously stirred for $2 \mathrm{~h}$ and the temperature maintained at $45^{\circ} \mathrm{C}$ to form l-menthol-HP- $\beta$-CD inclusion complex. Drying was carried out in a $\mathrm{FD}-1 \mathrm{C}-50$ freeze drier for $48 \mathrm{~h}$ at a temperature lower than $-50^{\circ} \mathrm{C}$ and pressure of around $20 \times 10^{-3}$ $\mathrm{kPa}$. After then, samples were washed with anhydrous ethanol and dried again. The dried l-menthol-HP- $\beta-C D$ inclusion complex was collected and stored in a desiccator at room temperature prior to further FTIR, XRD and TG analysis. 


\section{Fourier transform infrared (FTIR) spectroscopy}

FTIR spectra of 1-menthol, HP- $\beta$-CD, 1-menthol-HP- $\beta$-CD inclusion complex were characterized by IR spectrometer (IRAffinity-1, Shimadzu Company, Japan) in the frequency range of $4000-400 \mathrm{~cm}^{-1}$ with resolution of $2 \mathrm{~cm}^{-1}$.

\section{X-ray diffraction}

XRD patterns of 1-menthol, HP- $\beta-C D$ and 1-menthol-HP- $\beta$-CD inclusion compound were investigated by an X-ray diffractometer (D/Max 2000X, Rigaku Corporation, Japan). The patterns were recorded in the region of $2 \theta$ from $5^{\circ}$ to $70^{\circ}$ with $\mathrm{Cu} \mathrm{K \alpha}$ radiation at $40 \mathrm{kV}$ and $100 \mathrm{~mA}$.

\section{Molecular mechanics (MM) calculations}

In order to obtain information regarding the inclusion process, energy and structure of inclusion complexes, the formation of 1-menthol-HP- $\beta-C D$ inclusion complex at the molecular level is examined using MM2 calculations. Chem3D Ultra (CambridgeSoft Corporation, MA, USA) was used to calculate energies. Geometries of HP- $\beta-C D$, 1 -menthol and the 1-menthol-HP- $\beta-C D$ inclusion complex were optimized using MM2 calculations. After properly orienting HP- $\beta-\mathrm{CD}$ and 1-menthol, the inclusion process was simulated by successively changing the $\mathrm{Z}$ coordinate of the 1-menthol atoms. The position of the 1-menthol relative to the HP- $\beta-\mathrm{CD}$ is referred to the $\mathrm{Z}$ coordinate of one reference atom (C5 as shown in Figure 1(a)) of the guest. The 1-menthol moving direction during the

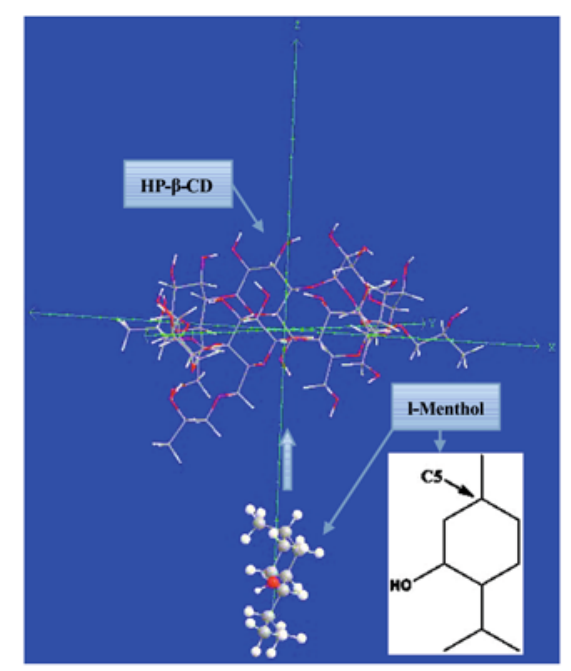

(a)
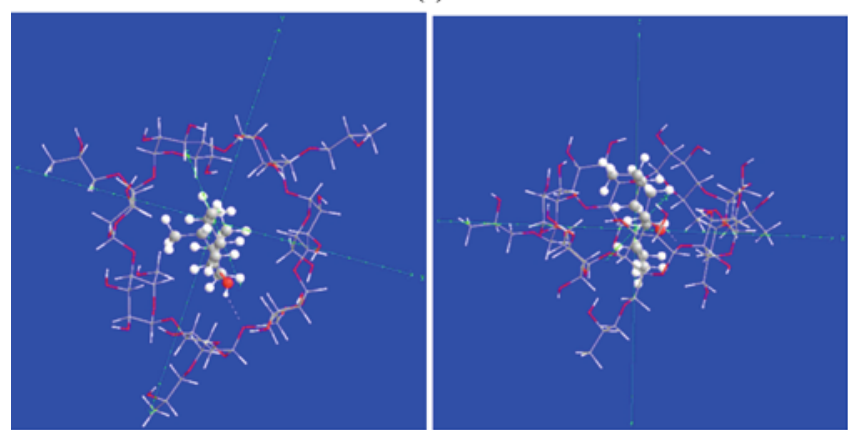

(b)

Figure 1. Moving direction of the l-menthol during the complexation processes (a), structures of the energy minima obtained by the MM2 calculations for the l-menthol-HP- $\beta-C D$ inclusion complex (b) complexation processes was shown in Figure 1(a). The labeled carbon atom (C5) of the 1-menthol molecule is used to express the relative position between the 1 -menthol and HP- $\beta$-CD when the 1-menthol passes through the cavity of the HP- $\beta-C D$.

\section{Thermogravimetric analysis}

The experiments were carried out in a TGA-Q5000IR thermogravimetric analyzer (TA Instruments, USA). In the experiment, approximately $5 \mathrm{mg}$ of dried sample was spread uniformly on the bottom of the ceramic crucible of the thermal analyzer. The pyrolysis experiment was performed at a heating rate of $5^{\circ} \mathrm{C} / \mathrm{min}$ in a dynamic high purity nitrogen flow of $20 \mathrm{ml} / \mathrm{min}$. The temperature of the furnace was programmed to rise from room temperature to $500^{\circ} \mathrm{C}$. The software used for TG/DTG was 'TA Universal Analysis'.

\section{RESULTS AND DISCUSSION}

FTIR results of l-menthol, HP- $\beta-C D$ and l-menthol-HP- $\beta-C D$ inclusion complex

Figure 2 shows the FTIR spectra of HP- $\beta-C D$, 1-menthol and $1-m e n t h o l-H P-\beta-C D$ inclusion complex.

In the curve of HP- $\beta-\mathrm{CD}$, there is a broad band locating at $3375 \mathrm{~cm}^{-1}$ which can be assigned to the stretching $(\mathrm{O}-\mathrm{H})$ vibration of hydroxyl group. The asymmetric $\left(\mathrm{CH}_{3^{-}}\right)$stretching vibration occurs at 2986 and $2899 \mathrm{~cm}^{-1}$. The stretching $(\mathrm{C}=\mathrm{O})$ vibration of the carbonyl group in saccharide appears at $1649 \mathrm{~cm}^{-1}$. The wagging $(\mathrm{C}-\mathrm{H})$ vibration appears at 1414 and $1369 \mathrm{~cm}^{-1}$. The band at $1339 \mathrm{~cm}^{-1}$ is attributed to bending $(\mathrm{O}-\mathrm{H})$ vibration. A shoulder band at $1151 \mathrm{~cm}^{-1}$ and a strong band at 1032 $\mathrm{cm}^{-1}$ can be assigned to stretching (C-O) vibration. The bands at 943, 854, 756 and 704 can be assigned to ring skeleton vibration ${ }^{\mathbf{1 4}, \mathbf{1 7}, 18}$.

In the curve of 1-menthol, the stretching $(\mathrm{O}-\mathrm{H})$ vibration of hydroxyl group occurs at $3252 \mathrm{~cm}^{-1}$. The bands observed at 2922 and $2870 \mathrm{~cm}^{-1}$ and the shoulder band at $2955 \mathrm{~cm}^{-1}$ are assigned as stretching $(\mathrm{C}-\mathrm{H})$ vibration. The bands at 1454 and $1371 \mathrm{~cm}^{-1}$ are due to deformation (C-H) vibration. The bending $(\mathrm{O}-\mathrm{H})$ vibration appears at 1352 and $1305 \mathrm{~cm}^{-1}$. The bands at 1173, 1092 and $1036 \mathrm{~cm}^{-1}$ are assigned as the stretching of $\mathrm{C}-\mathrm{O}$. The

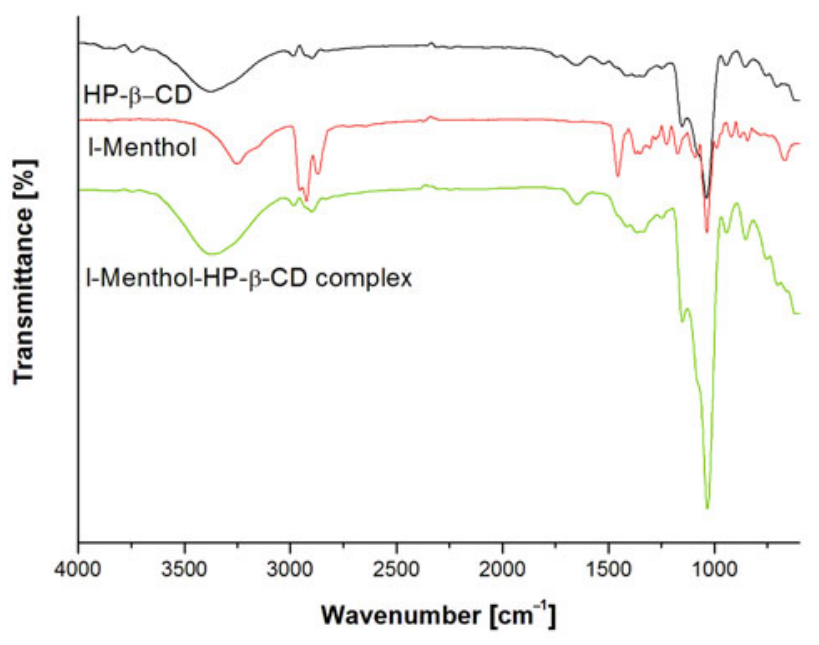

Figure 2. FTIR spectra of HP- $\beta-C D$, 1-menthol and 1-menthol-HP- $\beta-C D$ inclusion complex 
ring skeleton vibration occurs at 986, 920, 878, 843 and $669 \mathrm{~cm}^{-1} 19$.

The curve of $1-$ menthol-HP- $\beta-C D$ is similar to that of HP- $\beta-C D$. This indicates that the frame of HP- $\beta-C D$ in the complex is not changed. Encapsulation of 1-menthol does not significantly change the spectra of HP- $\beta-C D$. Compared with the curve of HP- $\beta-C D$, red shift can be observed in the curve of 1-menthol-HP- $\beta-C D$ inclusion complex. The stretching $(\mathrm{O}-\mathrm{H})$ vibration of hydroxyl group shifts from 3375 to $3360 \mathrm{~cm}^{-1}$. The antisymmetric $\left(\mathrm{CH}_{3^{-}}\right)$stretching vibration shifts from 2986 to $2984 \mathrm{~cm}^{-1}$. The stretching $(\mathrm{C}=\mathrm{O})$ vibration of the carbonyl group in saccharide shifts from 1649 to $1647 \mathrm{~cm}^{-1}$. The wagging (C-H) vibration shifts from 1414 and $1369 \mathrm{~cm}^{-1}$ to 1411 and $1366 \mathrm{~cm}^{-1}$ respectively ${ }^{\mathbf{1 4}, 17}$. In the curve of 1-menthol-HP- $\beta$-CD inclusion complex, the bands of 1-menthol at 2955, 2922, 2870, 987, 920, 878, 843 and 669 disappear or shift to other wave numbers. From these changes, it can be deduced that 1-menthol was encapsulated into the cavity of $\mathrm{HP}-\beta-\mathrm{CD}^{17}$.

\section{XRD RESULTS OF L-MENTHOL, HP-B-CD AND L-MENTHOL-HP-B-CD INCLUSION COMPLEX}

In order to see if in fact 1-menthol is encapsulated in HP- $\beta-C D$, XRD was also used to characterize l-menthol, HP- $\beta-C D$ and 1-menthol-HP- $\beta-C D$ inclusion complex. The curves of XRD are shown in Figure 3.

As shown in Figure 3, l-menthol is crystalline, HP$-\beta-\mathrm{CD}$ and 1-menthol-HP- $\beta-\mathrm{CD}$ inclusion complex are amorphous. 1-menthol has four relatively strong sharp peaks around $2 \theta=8.0^{\circ}, 14.0^{\circ}, 20.5^{\circ}$, and $21.6^{\circ}$. Some relatively small sharp peaks appear around $2 \theta=9.3^{\circ}$, $12.3^{\circ}, 16.2^{\circ}, 16.9^{\circ}, 19.0^{\circ}, 24.6^{\circ}, 25.0^{\circ}, 28.8^{\circ}, 29.5^{\circ}, 33.0^{\circ}$, $33.3^{\circ}, 36.0^{\circ}$, and $46.1^{\circ}$. The XRD patterns of HP- $\beta-C D$ and 1-menthol-HP- $\beta-C D$ inclusion complex are similar. No sharp peaks can be observed from the two curves. Furthermore, the sharp peaks of l-menthol disappear in the XRD pattern of 1-menthol-HP- $\beta$-CD inclusion complex. It can be inferred that 1-menthol was encapsulated in $\mathrm{HP}-\beta-\mathrm{CD}^{20}$.

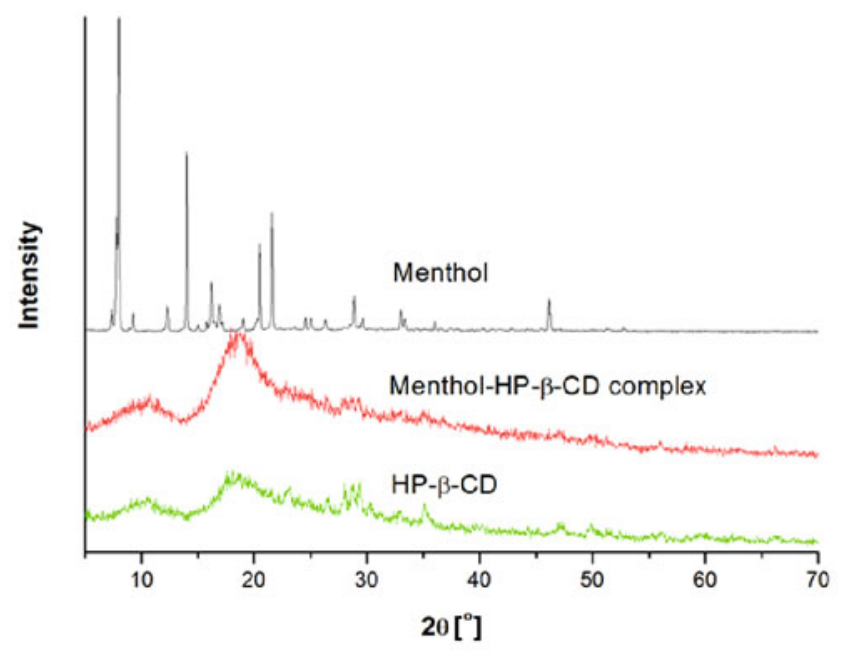

Figure 3. XRD patterns of HP- $\beta-C D$, 1 -menthol and 1-menthol$-\mathrm{HP}-\beta-\mathrm{CD}$ inclusion complex

\section{MM2 calculation results}

Molecular mechanics uses classical mechanics to model molecular systems. The potential energy of all systems in molecular mechanics is calculated using force fields. Molecular mechanics can give some information regarding the energy and structure of inclusion complexes ${ }^{14,19}$.

The interaction between 1-menthol and HP- $\beta-C D$, and the combination of the host and the guest are important for understanding the inclusion complex process. Binding energy (BE), as Eq. (1), is a concept to depict the combination energy ${ }^{17,21}$.

$B E=E_{\text {complex }}-E_{\text {guest }}-E_{\text {host }}$

where $E_{\text {complex }}$ is the total energy of the 1-menthol-HP$-\beta-\mathrm{CD}$ inclusion complex, $E_{\text {guest }}$ is the total energy of l-menthol, and $E_{\text {host }}$ is the total energy of HP- $\beta-C D$.

The initial docking strategy was to push l-menthol stepwise through HP- $\beta$-CD orifice minimizing the energy of the complex at each step. The l-menthol position throughout the study is referred to by the $Z$ coordinate of its $\mathrm{C} 5$ atom. Of course, other atoms can also be selected as reference atom.

There are several isomers of substituted HP- $\beta-C D$. The chemical structure of HP- $\beta$-CD provided by the supplier (Fisher Scientific) is 1,3,5-trisubstituted $\beta$-CD (Fig. 4), which may be the most stable conformation and has the lowest energy. Therefore, 1,3,5-trisubstituted $\beta$-CD is used in the calculation process. The energy variation associated with the inclusion process was computed for 1-menthol as shown in Figure 5.

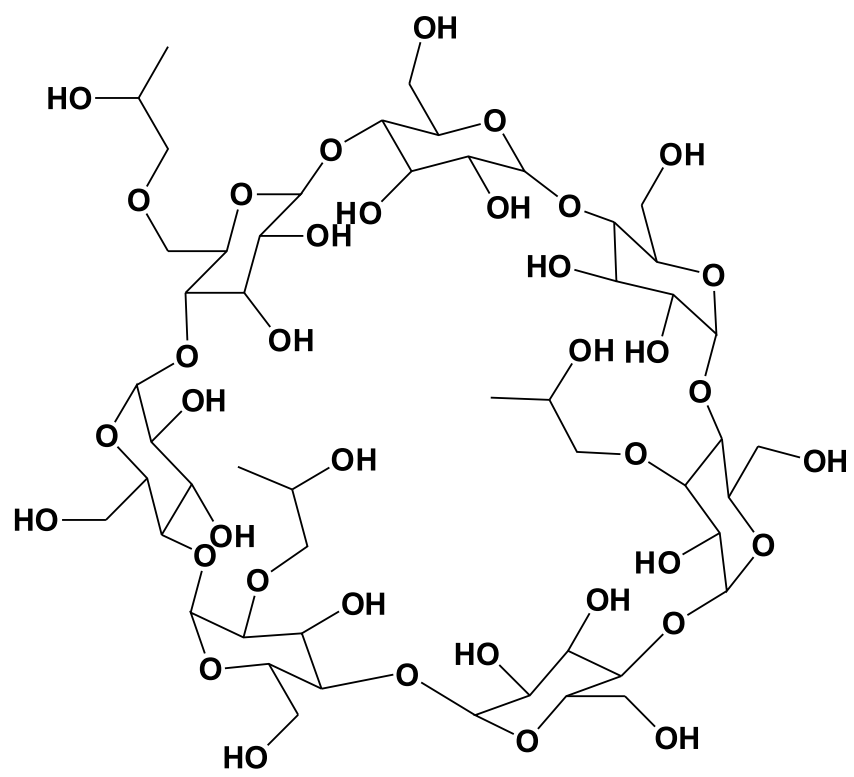

Figure 4. The structure of HP- $\beta$-CD (1,3,5-trisubstituted $\beta$-CD)

Figure 5 illustrates changes in the values of BE during pushing 1-menthol stepwise through HP- $\beta-C D$. There is a slight change in the number of $\mathrm{BE}$ when $\mathrm{Z}$ coordinate is in the range of $-20 \times 10^{-10} \mathrm{~m}$ to $-8 \times 10^{-10} \mathrm{~m}$. BE has a sharp fall when $\mathrm{Z}$ coordinate changes from $-8 \times$ $10^{-10} \mathrm{~m}$ to $3.5 \times 10^{-10} \mathrm{~m}$. At $3.5 \times 10^{-10} \mathrm{~m}$, BE decreases to the minimum value, $-127 \mathrm{~kJ} / \mathrm{mol}$. The negative $\mathrm{BE}$ value means energy release during inclusion complex formation. The more negative the binding energy is, the more thermodynamically favorable is the inclusion complex $^{22}$. The most stable 1-menthol-HP- $\beta-C D$ inclusion complex is at $3.5 \times 10^{-10} \mathrm{~m}$. The MM2-computed structures for energy minima are shown in Figure 1(b). 


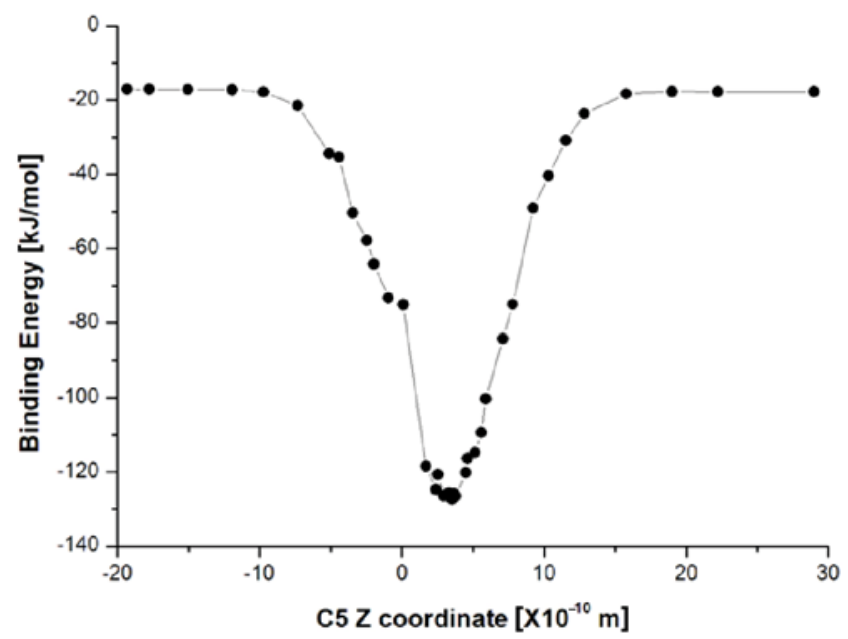

Figure 5. Plotting of calculated binding energy versus the $\mathrm{Z}$ coordinate of the C5 in 1-menthol

BE goes sharply up when $\mathrm{Z}$ coordinate changes from $3.5 \times 10^{-10} \mathrm{~m}$ to $12 \times 10^{-10} \mathrm{~m}$. There is a little change in the number of $\mathrm{BE}$ when $\mathrm{Z}$ coordinate is in the range of $12 \times 10^{-10} \mathrm{~m}$ to $30 \times 10^{-10} \mathrm{~m}$.

Once 1-menthol is included, HP- $\beta$-CD can change its shape and it does so to maximize the stabilization. l-menthol, the guest molecule, also made conformational adjustments to take maximum advantage of the weak van der Waals forces that exist and the complexation geometry of the guest was constantly re-adjusted until the most stable supramolecular interactions were gained during the MM2 calculations and, finally, the energy changes were recorded. The binding of guest l-menthol molecule within the host HP- $\beta-C D$ is not fixed or permanent but rather is a dynamic equilibrium. Binding strength depends on how well the 'host-guest' complex fits together and on specific local interactions between surface atoms, such as van der Waals forces, hydrophobic interactions and hydrogen bonds ${ }^{21}, 23$.

Pyrolysis release characteristics of I-HP- $\beta$-CD inclusion complex

Figure 6 shows the weight loss and the rate of weight loss curve obtained during the pyrolysis of l-menthol, blank HP- $\beta-C D$ and l-menthol-HP- $\beta$-CD inclusion complex under inert nitrogen atmosphere.

The thermogravimetry (TG) and derivative thermogravimetry (DTG) curves of blank HP- $\beta-C D$ and 1-menthol-HP- $\beta$-CD are shown in Figure 6. Three stages can be distinguished from the TG curves of blank HP- $\beta$ $-\mathrm{CD}$ and l-menthol-HP- $\beta-\mathrm{CD}$. The first stage goes from room temperature to $291.9^{\circ} \mathrm{C}$. The second stage goes from 291.9 to $405^{\circ} \mathrm{C}$ and two strong peaks at $361^{\circ} \mathrm{C}$ are observed in the DTG curves in this stage. At the strong peak temperature, the rate of weight loss attained the maximum value. Most of HP- $\beta$-CD was decomposed in the second stages. The third stage goes from $405^{\circ} \mathrm{C}$ to the final temperature $\left(500^{\circ} \mathrm{C}\right)$ of the experiment. The solid residuals of HP- $\beta-C D$ continuously decomposed at a very slow rate in the third stages. The TG curve l-menthol-HP- $\beta-C D$ inclusion complex is downward sloping from room temperature to $291.9^{\circ} \mathrm{C}$. Compared to the pyrolysis characteristic of 1-menthol-HP- $\beta-C D$ inclusion complex, the TG curve of blank HP- $\beta-C D$ shows a leveling off in this temperature range. The difference of TG curves in this temperature range is due to release of l-menthol. The weight loss of blank HP- $\beta-C D$ is $1.48 \%$. The slight weight loss was mainly attributed to desorption of moisture as bound water on the surface and the cavities of HP- $\beta-C D$. The weight loss of 1 -menthol-HP- $\beta$-CD inclusion complex is $8.44 \%$. Because of the hydrophobic character of l-menthol molecule and hydrophobic inner cavity of HP- $\beta-C D$, all the water molecules might be expelled from the internal cavity to the $\mathrm{CD}$ periphery during the inclusion process and the water that is included in 1-menthol-HP- $\beta-C D$ inclusion complex can be ignored ${ }^{14,19}$. Therefore, the weight loss of l-menthol-HP- $\beta-C D$ inclusion complex in the first stage is mainly attributed to release of l-menthol. The 1 -menthol loading capacity (defined as the mass ratio of 1 -menthol encapsulated in HP- $\beta$-CD to l-menthol-HP- $\beta$ -CD inclusion complex), about $8.44 \%$, can be estimated from the value of weight loss of 1-menthol-HP- $\beta-C D$ inclusion complex.

Two small peaks can be distinguished in the DTG curve of l-menthol-HP- $\beta-\mathrm{CD}$ inclusion complex from room temperature to $291.9^{\circ} \mathrm{C}$. The temperature range of the first small peak is from 31.9 to $140.6^{\circ} \mathrm{C}$. At this temperature range, weight loss of l-menthol-HP- $\beta-\mathrm{CD}$ inclusion complex is $4.06 \%$. The first peak temperature is $69.3^{\circ} \mathrm{C}$, with the temperature the rate of 1-menthol release attains maximum value $\left(0.06844 \% /{ }^{\circ} \mathrm{C}\right)$. The second peak temperature is $279.1^{\circ} \mathrm{C}$, and at this temperature the rate of l-menthol release attains maximum value $\left(0.1598 \% /{ }^{\circ} \mathrm{C}\right)$. The temperature range of the second small peak is from 215.1 to $291.9^{\circ} \mathrm{C}$. At this temperature range, the weight loss of 1-menthol-HP- $\beta$-CD inclusion complex is $4.18 \%$. The two small peaks are due to release of 1-menthol encapsulated in HP- $\beta-C D$. During the inclusion process, the position of the l-menthol relative to HP- $\beta-C D$ may be different. Thus, the combination of 1-menthol and HP- $\beta$ $\mathrm{CD}$ are different. Therefore, during the heating process of 1-menthol-HP- $\beta$-CD inclusion complex, two small peaks in the rate of weight loss curve can be observed.

l-menthol vaporized quickly and almost completely before $110^{\circ} \mathrm{C}$ during thermal degradation of process. A similar result was also reported in literature ${ }^{7}$. However, some 1-menthol still released from l-menthol-HP- $\beta$-CD inclusion complex in the temperature range of 215.1 to $291.9^{\circ} \mathrm{C}$. This indicated that thermal stability of l-menthol was enhanced by the encapsulation technology. The sensory character of 1-menthol and 1-menthol-HP- $\beta-C D$ inclusion complex was smelled by nose. The odor of 1-menthol alone cannot be detected after 6 days; while 1 -menthol-HP- $\beta-C D$ inclusion complex still has characteristic odor of l-menthol after 4 month. This phenomenon indicated that the shelf-life of 1-menthol was improved by encapsulation of 1-menthol in HP- $\beta-C D$.

\section{Pyrolysis kinetic parameters of l-menthol-HP- $\beta$-CD inclusion complex}

The use of thermogravimetric data to evaluate kinetic parameters of solid state reactions was reported in a number of literatures ${ }^{\mathbf{1 5 , 1 6}}$. The pyrolysis reaction of the 1-menthol-HP- $\beta$-CD inclusion complex can be simply expressed by Eq. (2).

x l-menthol-HP- $\beta$-CD (s) $\rightarrow$ y l-menthol $(\mathrm{g})+$

$+\mathrm{z}$ HP- $\beta$-CD (s) 
The rate expression for the disappearance of 1-menthol-HP- $\beta$-CD in the reaction as shown in Eq. (2) may be expressed by:

$\frac{d \alpha}{d t}=k(1-\alpha)^{n}$

where $\alpha$ is the fraction of 1-menthol-HP- $\beta$-CD decomposed at time $t, n$ is the order of reaction, and $k$ is the rate constant.

The integrated form of Eq. (3) can be expressed as Eq. (4) and Eq. (5) according to Coats - Redfern method ${ }^{24,25}$.

$\ln \left[\frac{1-(1-\alpha)^{1-n}}{T^{2}(1-n)}\right]=\ln \left(\frac{A R}{\beta E}\right)-\frac{E}{R T} \quad($ for $\mathrm{n} \neq 1)$

$\ln \left[\frac{-\ln (1-\alpha)}{T^{2}}\right]=\ln \left(\frac{A R}{\beta E}\right)-\frac{E}{R T} \quad($ for $\mathrm{n}=1)$

where $A$ is the pre-exponential factor, $E$ is the activation energy, $R$ is the gas constant, $\beta$ is the heating rate, and $T$ is the absolute temperature.

Thus a plot of either $\ln \left[\left(1-(1-\alpha)^{1-\mathrm{n}}\right) / T^{2} /(1-\mathrm{n})\right]$ against $1 / T$ or, where $n=1, \ln \left[-\ln (1-\alpha) / T^{2}\right]$ against $1 / T$ should result in a straight line of slope $-E / R$ for correct value of $n$. From the slope and intercept of a line, the apparent activation energy and the pre-exponential factor of the dynamic degradation at various conversions can be estimated.

There are two small peaks, which are due to l-menthol encapsulated in HP- $\beta-C D$, in the rate of weight loss curve of the 1-menthol-HP- $\beta$-CD inclusion complex from room temperature to $291.9^{\circ} \mathrm{C}$ as shown in Figure 6. In the experiments, different $\mathrm{n}$ were adopted for l-menthol-HP- $\beta$-CD inclusion complex to fit straight line. All the squared values of linear correlation coefficients $\left(\mathrm{R}^{2}\right)$ alculated from Eq. (4) and Eq. (5) by fitting the experiment data are shown in Table 1.

The closer are the squared values of linear correlation coefficients to 1 , the better the linear relationship between $\ln \left[\left(1-(1-\alpha)^{1-n}\right) / \mathrm{T}^{2} /(1-\mathrm{n})\right]$ or $\ln \left[-\ln (1-\alpha) / \mathrm{T}^{2}\right]$ and $1 / \mathrm{T}$ should be. When reaction orders, $n$, are 2 and 0 for peaks at 69.3 and $279.1^{\circ} \mathrm{C}$ respectively, the squared values of linear correlation coefficients are relatively closer to 1 . Therefore, 2 and 0 were adopted as the pyrolysis reaction orders for peaks at 69.3 and $279.1^{\circ} \mathrm{C}$ respectively. The plots of $\ln \left[\left(1-(1-\alpha)^{1-n}\right) /\left(T^{2}(1-n)\right)\right]$ against $1 / \mathrm{T}$ are shown in Figure 6.

As shown in Figure 7 and 8, when the values of reaction order are 2 and 0 for peaks at 69.3 and $279.1^{\circ} \mathrm{C}$ respectively, there are good linear relationships between $\ln \left[\left(1-(1-\alpha)^{1-n}\right) / T^{2} /(1-n)\right]$ and $1 / \mathrm{T}$. All the plots have high linear correlation coefficients and the values of $\mathrm{R}^{2}$ are greater than 0.99 .

From the slope of the line, the apparent activation energy can be estimated. The pre-exponential factor can be calculated from the intercept of the line. The values of activation energy and pre-exponential factor obtained from the slope and intercept of the lines by fitting the

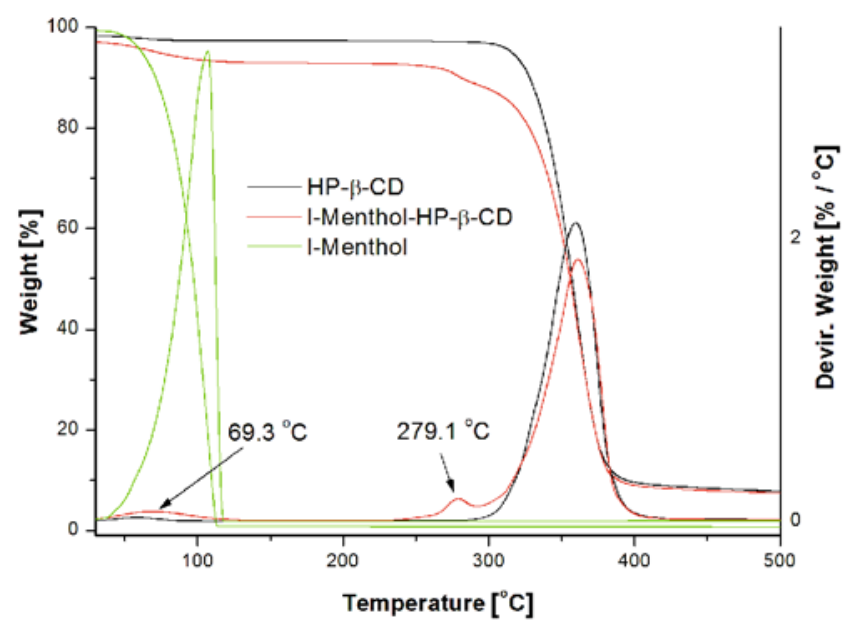

Figure 6. TG-DTG curves of 1-menthol, blank HP- $\beta-C D$ and l-menthol-HP- $\beta$-CD inclusion complex

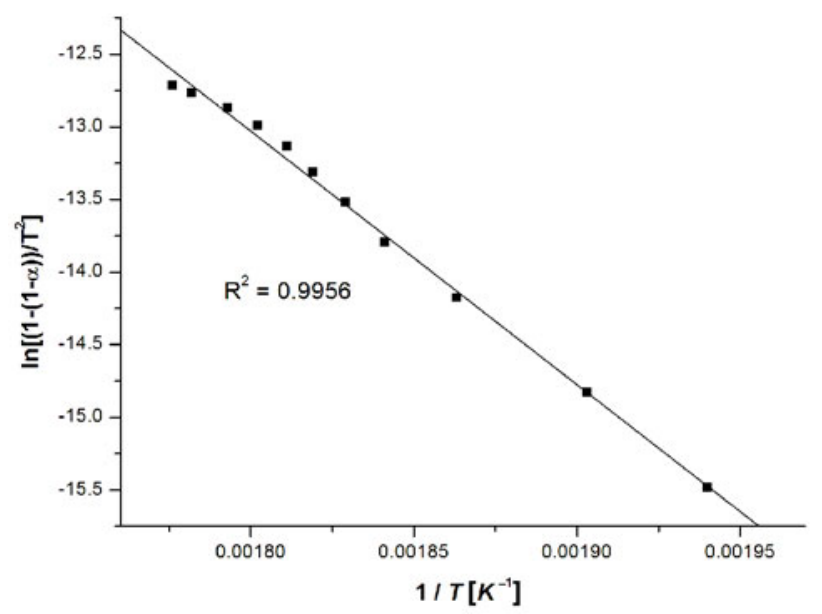

Figure 7. Plots of $\ln \left[\left(1-(1-\alpha)^{1-n}\right) / T^{2} /(1-n)\right]$ vs. $1 / T$ (n is 0 in the temperature range of $215.1-291.9^{\circ} \mathrm{C}$ )

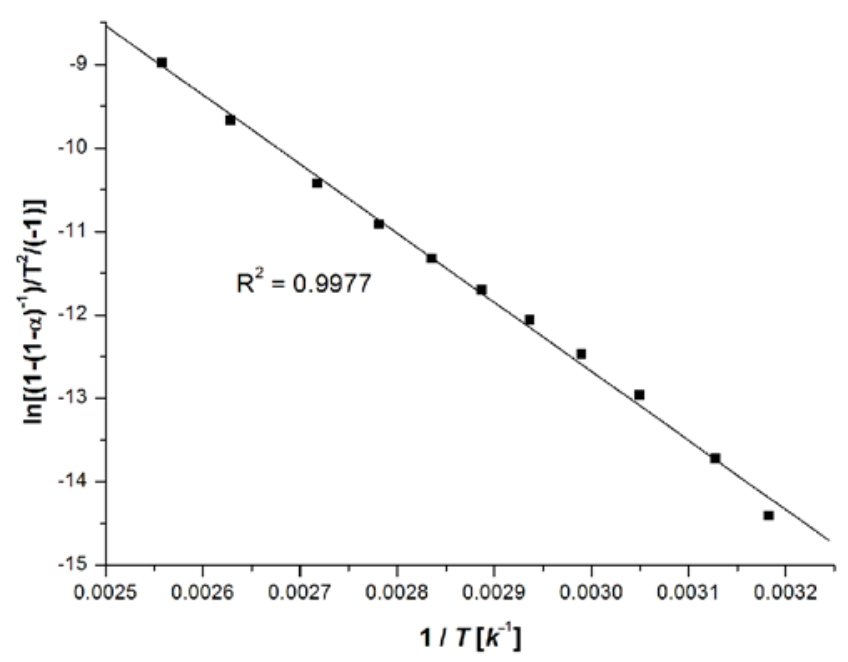

Figure 8. Plots of $\ln \left[\left(1-(1-\alpha)^{1-n}\right) / T^{2} /(1-n)\right]$ vs. $1 / T$ (n is 2 in the temperature range of $\left.31.9-140.6^{\circ} \mathrm{C}\right)$

Table 1. The squared values of linear correlation coefficients $\left(\mathrm{R}^{2}\right)$

\begin{tabular}{|l|c|c|c|c|c|c|c|}
\hline Peak temperature, $\left[{ }^{\circ} \mathrm{C}\right]$ & $\mathrm{n}=0$ & $\mathrm{n}=0.5$ & $\mathrm{n}=1$ & $\mathrm{n}=1.5$ & $\mathrm{n}=2$ & $\mathrm{n}=2.5$ & $\mathrm{n}=3$ \\
\hline 69.3 & 0.8482 & 0.9133 & 0.9616 & 0.9887 & 0.9977 & 0.9957 & 0.9889 \\
\hline 279.1 & 0.9956 & 0.9946 & 0.9828 & 0.9621 & 0.9351 & 0.9058 & 0.8775 \\
\hline
\end{tabular}


experiment data according to Eq. (4) and Eq. (5) are given in Table 2.

Table 2. The values of apparent activation energy and reaction order

\begin{tabular}{|c|c|c|c|c|}
\hline $\mathrm{n}$ & $T\left[{ }^{\circ} \mathrm{C}\right]$ & $\alpha[\%]$ & $E[\mathrm{~kJ} / \mathrm{mol}]$ & $A$ \\
\hline 2 & $41.1-117.8$ & $5-95$ & 66.9 & $7.79 \times 10^{9}$ \\
\hline 0 & $242.3-289.9$ & $5-95$ & 145.3 & $1.77 \times 10^{13}$ \\
\hline
\end{tabular}

As shown in Table 2, the activation energy and preexponential factor values of the peak at $69.3^{\circ} \mathrm{C}$ in the temperature range from 41.1 to $117.8^{\circ} \mathrm{C}$ are relatively small compared with those of the peak at $279.1^{\circ} \mathrm{C}$ in the temperature range from 242.3 to $289.9^{\circ} \mathrm{C}$. Different apparent activation energy means different reactions. Low activation energy means a fast reaction and high activation energy means a slow reaction according to the Arrhenius equation ${ }^{26}$. Small activation energy indicates that l-menthol easily releases from the inclusion complex and the l-menthol-HP- $\beta-\mathrm{CD}$ inclusion complex is instable, while high activation energy implies that 1 -menthol is bound to HP- $\beta-C D$ firmly and the 1-menthol-HP- $\beta-C D$ inclusion complex is relatively stable. During the inclusion process, the position of the 1-menthol relative to HP- $\beta-C D$, and the combination of 1-menthol and HP$-\beta-C D$ may be different. It leads to different activation energy and pre-exponential factor as shown in Table 2.

The activation energy is positive. It means that energy is required to disassemble a whole 1-menthol-HP- $\beta-C D$ inclusion complex into separate parts. Compared with activation energy, $\mathrm{BE}$ is negative. This indicates that energy released after l-menthol entering into the cavity of HP- $\beta$-CD. Compared with pyrolysis activation energy $(66.9 \mathrm{~kJ} / \mathrm{mol})$ of the first peak at $69.3^{\circ} \mathrm{C}$, the value of minimum binding energy $(-127 \mathrm{~kJ} / \mathrm{mol})$ calculated is close to that of pyrolysis activation energy $(145.3 \mathrm{~kJ} /$ mol) of the second peak at $279.1^{\circ} \mathrm{C}$. It indicates that the l-menthol-HP- $\beta-C D$ inclusion complex represented by the peak $279.1^{\circ} \mathrm{C}$ is relatively stable.

\section{CONCLUSIONS}

This paper concentrates on the production and characterization of 1-menthol-HP- $\beta-C D$ inclusion complex. The inclusion complex was successfully obtained. The results of FTIR and XRD confirm that l-menthol enter the cavities of HP- $\beta$-CDs. The l-menthol loading capacity was determined by TG analysis, and the value is about $8.44 \%$. 1-menthol release from the 1-menthol-HP- $\beta-C D$ inclusion complex mainly occurs from room temperature to $291.9^{\circ} \mathrm{C}$. At 69.3 and $279.1^{\circ} \mathrm{C}$, two l-menthol release rate peaks can be distinguished in the DTG curve of l-menthol-HP- $\beta$-CD inclusion complex. The l-menthol release reaction order, activation energy and the preexponential factor were determined. Geometries of l-menthol, HP- $\beta$-CD and l-menthol-HP- $\beta$-CD inclusion complex were optimized using MM2 calculations. The binding energies of the 1-menthol-HP- $\beta-C D$ inclusion complexes were obtained. The minimum binding energy is $-127 \mathrm{~kJ} / \mathrm{mol}$ at $3.5 \times 10^{-10} \mathrm{~m}$. The most stable 1 -menthol-HP- $\beta$-CD inclusion complex is in this situation. The shape and orientation of the most stable complex were presented.

\section{ACKNOWLEDGEMENTS}

This work was financially supported by the National Natural Science Fund of China (No. 21276157, No. 21476140) and the Shanghai Plateau Discipline "Chemical Engineering and Technology (Perfume and Aroma Technology)".

\section{LITERATURE CITED}

1. Kamatou, G.P.P., Vermaak, I., Viljoen, A.M. \& Lawrence, B.M. (2013). Menthol: A simple monoterpene with remarkable biological properties. Phytochemistry 96, 15-25. DOI: 10.1016/j.phytochem.2013.08.005.

2. Plößer, J., Lucas, M. \& Claus, P. (2014). Highly selective menthol synthesis by one-pot transformation of citronellal using Ru/H-BEA catalysts. J. Catal. 320, 189-197. DOI: 10.1016/j.jcat.2014.10.007.

3. Hiki, N., Kaminishi, M., Hasunuma, T., Nakamura, M., Nomura, S., Yahagi, N., Tajiri, H. \& Suzuki, H. (2011). A phase I study evaluating tolerability, pharmacokinetics, and preliminary efficacy of 1-menthol in upper gastrointestinal endoscopy. Clin. Pharmacol. The. 90, 221-338. DOI: 10.1038/clpt.2011.110.

4. Liu, Z., Shen, C., Tao, Y., Wang, S., Wei, Z., Cao, Y., Wu, H., Fan, F., Lin, C., Shan, Y., Zhu, P., Sun, L., Chen, C., Wang, A., Zheng, S. \& Lu, Y. (2015). Chemopreventive efficacy of menthol on carcinogen-induced cutaneous carcinoma through inhibition of inflammation and oxidative stress in mice. Food Chem. Toxicol. 82, 12-18. DOI: 10.1016/j.fct.2015.04.025.

5. Soottitantawat, A., Takayama, K., Okamura, K., Muranaka, D., Yoshii, H., Furuta, T., Ohkawara, M. \& Linko, P. (2005). Microencapsulation of 1-menthol by spray drying and its release characteristics. Innov. Food Sci. Emerg. 6, 163-170. DOI: 10.1016/j.ifset.2004.11.007.

6. Zhu, G., Xiao, Z., Zhou, R. \& Niu, Y. (2016). Kinetics and release characteristics of menthyl acetate from its $\beta$-cyclodextrin inclusion complex by thermogravimetric analysis. J. Incl. Phenom. Macrocycl. Chem. 84, 219-224. DOI: 10.1007/s10847-016-0599-y.

7. Mortenson, M.A. \& Reineccius G.A. (2008). Encapsulation and release of menthol. Part 2: direct monitoring of L-menthol release from spray-dried powders made with OSAn-substituted dextrins and gum acacia. Flavour Fragr. J. 23, 407-415. DOI: 10.1002/ffj.1892.

8. Liu X.D., Furuta, T., Yoshii, H., Linko, P. \& Coumans, W.J. (2000). Cyclodextrin encapsulation to prevent the loss of l-menthol and its retention during drying. Biosci. Biotechnol. Biochem. 64, 1608-1613. DOI: 10.1271/bbb.64.1608.

9. Kayaci, F. \& Uyar, T. (2012). Encapsulation of vanillin/ cyclodextrin inclusion complex in electrospun polyvinyl alcohol (PVA) nanowebs: Prolonged shelf-life and high temperature stability of vanillin. Food Chem. 133, 641-649. DOI: 10.1016/j.ifset.2004.11.007.

10. Carrier, R.L., Miller, L.A. \& Ahmed, I. (2007). The utility of $\beta$-cyclodextrins for enhancing oral bioavailability, $J$. Control. Rel. 123, 78-99. DOI: 10.1016/j.jconrel.2007.07.018.

11. Rassu, G., Soddu, E., Cossu, M., Brundu, A., Cerri, G., Marchetti, N., Ferraro, L., Regan, R.F., Giunchedi, P., Gavini, E. \& Dalpiaz, A. (2015). Solid microparticles based on chitosan or methyl- $\beta$-cyclodextrin: A first formulative approach to increase the nose-to-brain transport of deferoxamine mesylate. J. Control. Rel. 201, 68-77. DOI: 10.1016/j. jconrel.2015.01.025.

12. Hsu, C.M., Tsai, F.J. \& Tsa, Y. (2014). Inhibitory effect of Angelica sinensis extract in the presence of 2-hydroxypropyl$\beta$-cyclodextrin. Carbohyd. Polym. 114, 115-122. DOI: 10.1016/j.carbpol.2014.07.042. 
13. Ol'khovich, M.V., Sharapova, A.V., Lavrenov, S.N., Blokhina, S.V. \& Perlovich, G.L. (2014). Inclusion complexes of hydroxypropyl- $\beta$-cyclodextrin with novel cytotoxic compounds: Solubility and thermodynamic properties. Fluid Phase Equilibr. 384, 68-72. DOI: 10.1016/j.fluid.2014.10.030.

14. Zhu, G., Feng, N., Xiao, Z., Zhou, R. \& Niu, Y. (2015). Production and pyrolysis characteristics of citralmonochlorotriazinyl- $\beta$-cyclodextrin inclusion complex. $J$. Therm. Anal. Calorim. 120, 1811-1817. DOI: 10.1007/ s10973-015-4498-z.

15. Zhu, G., Xiao, Z., Zhou, R. \& Feng, N. (2015). Production of a transparent lavender flavour nanocapsule aqueous solution and pyrolysis characteristics of flavour nanocapsule. J. Food Sci. Technol. 52, 4607-4612. DOI: 10.1007/ s13197-014-1465-9.

16. Zhu, G., Xiao, Z., Zhou, R. \& Zhu, Y. (2014). Study of production and pyrolysis characteristics of sweet orange flavour- $\beta$-cyclodextrin inclusion complex. Carbohyd. Polym. 105, 75-80. DOI: 10.1016/j.carbpol.2014.01.060.

17. Chen, Q. \& Guo, P. (2009). Inclusion compound of menthol with hydroxypropyl- $\beta$-cyclodextrin by infrared spectroscopy. Cent. South Pharm. 7, 749-752. (In Chinese).

18. Yuan, C. \& Jin, Z.Y. (2007). Study on configuration of hydroxypropyl- $\beta$-cyclodextrin, J. Food Sci. Biotech. 26, 34-36. (In Chinese).Lipkowitz, K.B. (1998). Applications of computational chemistry to the study of cyclodextrins. Chem. Rev. 98, 1829-1873. DOI: 10.1021/cr9700179.

19. Trivedi, M.K., Patil, S., Mishra, R.K. \& Jana, S. (2015). Structural and physical properties of biofield treated thymol and menthol. J. Mol. Pharm. Proc. Res. 3, 127. DOI: 10.4172/2329-9053.1000127.

20. Zeng, Z., Fang, Y. \& Ji, H. (2012). Side chain influencing the interaction between $\beta$-cyclodextrin and vanillin. Flav. Fragr. J. 27, 378-85. DOI: 10.1002/ffj.3115.

21. Chai, K. \& Ji, H. (2014). Inclusive seperation of acetophenone from petrochemical by-product with 1-phenylethanol via noncovalent interactions. AIChE J. 60, 2962-2975. DOI: 10.1002/aic.14474.

22. Yang, Z., Zeng, Z., Xiao, Z. \& Ji, H. (2014). Preparation and controllable release of chitosan/vanillin microcapsules and their application to cotton fabric. Flav. Fragr. J. 29, 114-120. DOI: 10.1002/ffj.3186.

23. Zhu, G., Xiao, Z., Zhou, R. \& Niu, Y. (2015). Pyrolysis Characteristics and kinetics of cyclodextrin and its two derivatives. Pol. J. Chem. Technol. 17, 1-4. DOI: 10.1515/ pjct-2015-0061.

24. Coats, A.W. \& Redfern, J.P. (1964). Kinetic parameters from thermogravimetric data. Nature 201, 68-69.

25. Levine, I.N. (2012). Physical Chemistry (6th ed.). Beijing, China: Tsinghua University Press limited. 